\title{
MORALITAS DALAM ERA CITIZEN JOURNALISM
}

\author{
Rarasaning Satianingsih ${ }^{1)}$ dan Sunu Catur Budiyono ${ }^{2)}$ \\ ${ }^{1,2}$ FKIP Universitas PGRi Adi Buana Surabaya \\ Email: ${ }^{1}$ rarasaning.setyaningsih@gmail.com, ${ }^{2}$ sunu@unipasby.ac.id
}

\begin{abstract}
Abstrak
Dalam era disruptif sekaligus merupakan era citizen journalism di mana setiap warga menjadi jurnalis sekaligus pembaca. Setiap individu bertanggung jawab atas pernyataan dan gagasan yang dipublikasikan di ruang publik serta berpengaruh terhadap pembacanya. Dalam situasi seperti itu, dituntut integritas individu terhadap nilai-nilai moral berkaitan dengan sesuatu yang dipublikasikan di masyarakat. Penelitian ini menggunakan metode survey dengan subjek penelitian mahasiswa PGSD dan PBI. Tujuan untuk mengetahui derajat moralitas mahasiswa terkait dengan citizen journalism. Hasil studi kasus terhadap mahasiswa PGSD dan PBI menyatakan di era masyarakat terbuka, moralitas individu dituntut untuk semakin kokoh. Walaupun disadari bahwa moralitas merupakan sesuatu yang cair (liquid) serta menjadi milik bersama, karena itu setiap individu memiliki peran mengawal dan menyajikan moral dalam bingkai moralitas yang paripurna. Sosial media merupakan ruang pertemuan berbagai macam nilai, kultural, dan interest dari berbagai elemen yang ada di masyarakat. Sosial media merupakan ruang pertarungan di mana moral atau nilai-nilai tidak boleh kalah agar standar kebajikan atau moralitas tetap terjaga dengan baik.
\end{abstract}

Kata Kunci: Citizen journalism, moralitas, sosial media.

\begin{abstract}
in the disruptive era and at the same time the citizen journalism, where everyone is both a journalist and a reader. Each individual is responsible for his or her public spaces and ideas that affect his readers. In such situations, individual integrity to moral values is required in connection with something publicly publicized. The study of this method of survey with the subjects of student PGSD and PBI studies. The goal is to know a student's degree of morality related to citizen journalism. The case study of PGSD and PBI students states that in an era of open society, individual morality is required to grow stronger. Although it is recognized that morality is liquid and belongs together, Thus each individual has a role of guarding and presenting morals in a standard framework of morality. Social media is a confed hall of all sorts of values, cultures, and interests from intermingling elements of society. Social media is a form of fighting where morals or values must not be beaten to keep a standard of virtue or morality properly preserved.
\end{abstract}

Keywords : citizen journalism, morality, social media. 


\section{PENDAHULUAN}

Mengapa moralitas perlu dikedepankan dalam era jurnalistik 4.0 atau era citizen journalism? Adanya panutan nilai, moral, dan norma dalam diri manusia dan kehidupan akan sangat menentukan totalitas diri individu atau jati diri manusia, lingkungan sosial, dan kehidupan individu. Oleh karena itu, nilai atau norma yang mengarah pada pembentukan moral yang sesuai dengan norma-norma kebenaran dan nilai-nilai kebajikan menjadi sesuatu yang esensial bagi pengembangan manusia utuh dalam konteks sosialnya. Ini mengingat bahwa dunia afektif yang ada pada setiap manusia harus selalu dibina secara berkelanjutan, terarah, dan terencana sehubungan dengan sifatnya yang labil, konstruktivis, dan kontekstual.

Moral diinternalisasi dan dieksternalisasi dalam pengalaman bermasyarakat yang terus menerus berproses, maka konstruksi moral terarah pada bentuk penghayatan (erlebniss) (Berger, 1990) dan pemahaman (verstehen) (Weber, 1998) terhadap kehidupan bermasyarakat secara menyeluruh dengan segala aspeknya (kognitif, afektif, psikomotor, emosional, dan intuitif). Dengan kata lain, moral eksis, tumbuh, dan berkembang dalam kehidupan sehari-hari, pergaulan sosial, ataupun pertemuan dengan yang lain (encounter) (Goffman, 1959) yang diungkapkan secara sosial lewat pelbagai tindakan sosial (Weber, 1998). Moral sebagai fakta sosial (Durkhim dalam Ritzer 2012: 132) bersifat objektif, coercive (menekan), dan eksternal yang berada dalam proses dialektika eksternalisasi, objektivasi, dan internalisasi individu maupun kolektif. Dalam proses dialektika, ketiga momen tersebut tidak berlangsung secara berurutan tetapi masyarakat (dalam kehidupan sehari-hari) dengan segala aspeknya dikarakterisasi ketiga momen itu secara serentak. Demikian juga sebaliknya, anggota masyarakat secara individu, serentak dalam menginternalisasikan dunia sosial sekaligus mengeksternalisasikannya sebagai suatu kenyataan obyektif. Dengan kata lain, individu berada dalam masyarakat, berarti berpartisipasi dalam dialektika tersebut (Berger, 1990:185; Titus, 1954; Nucci, 2008). Moral dalam posisinya sebagai objektivasi dari proses eksternalisasi dan internalisasi maka ia dikonstruksi, didekonstruksi, dan direkonstruksi oleh individu maupun kolektif sesuai dengan perspektif, parameter, dan konteks terjadinya proses sosial. Dengan demikian, moral dengan segala parameternya bukanlah sesuatu yang tetap di sepanjang waktu, tempat, dan maknanya.

Sasaran moralitas dalam citizen journalism pada umumnya dapat diarahkan untuk (a) membina dan menanamkan nilai moral dan norma, (b) meningkatkan dan memperluas tatanan nilai keyakinan seseorang atau kelompok, (c) meningkatkan kualitas diri manusia, kelompok atau kehidupan, (d) menangkal, memperkecil dan meniadakan halhal yang negatif, (e) membina dan mengupayakan terlaksananya dunia yang diharapkan (the expected world), (f) melakukan klarifikasi nilai intrinsik dari suatu nilai moral dan norma serta kehidupan secara umum (Kosasih Djahiri, 1992).

\section{METODE PENELITIAN}

Penelitian ini merupakan studi kasus, pada mahasiswa PGSD dan PBI. Studi kasus berupaya mencari kebenaran ilmiah dengan cara mempelajari secara mendalam dalam jangka waktu tertentu. Dalam hal ini, bukan 
banyaknya individu dan rerata yang menjadi dasar pertimbangan penarikan kesimpulan melainkan didasarkan ketajaman peneliti melihat kecenderungan, pola, arah, interaksi banyak factor, serta faktor pendorong dan penghambat (Muhadjir, 2002:55).

Teknik pengumpulan data dengan menggunakan observasi, in-depth interview, content analysis (de Vaus, 2002:23). Observasi digunakan untuk melihat perilaku dan tindakan mahasiswa dalam berkomunikasi di media sosial. Selanjutnya In-depth interview untuk mengetahui argumentasi atau alasan mahasiswa dalam melakukan tindakan tertentu terkait dengan tahap moralitas. Sedangkan content analysis untuk memahami isi unggahan mahasiswa di media sosial.

Data dianalisis secara deskriptif untuk mengeksplorasi argumentasi mahasiswa dalam moralitas mereka. Berdasarkan argumentasi yang mereka sampaikan kemudian kita cocokkan dengan parameter moralitas yang dikemukakan oleh Kohlberg (Kohlberg, 1977:35).

\section{HASIL DAN PEMBAHASAN}

Untuk dapat melakukan pendidikan moral tidak hanya terbatas pada lingkungan sekolah oleh guru saja. Pendidikan moral dapat dilakukan oleh siapa saja, kapan saja, dan di mana saja. Pada umumnya, terdapat tiga lingkungan yang amat kondusif untuk melaksanakan pendidikan moral, yakni lingkungan keluarga, lingkungan pendidikan, dan lingkungan masyarakat. Walaupun demikian, di era citizen journalism persoalan moral harus ditanamkan dalam segala sisi kehidupan sehingga individu memiliki integritas moral yang kuat.
Dalam pandangan Dobbert dan Winkler (1985), lingkungan keluarga merupakan faktor dominan yang efektif dan terpenting. Peran keluarga dalam pendidikan nilai adalah mendukung terjadinya proses identifikasi, internalisasi, panutan, dan reproduksi langsung dari nilai-nilai moral yang hendak ditanamkan sebagai pola orientasi dari kehidupan keluarga. Lingkungan keluarga dengan demikian menjadi lahan paling subur untuk menumbuhkembangkan pendidikan moral. Ini mengisyaratkan bahwa perubahan melalui reformasi dalam bidang sosial, politik, ekonomi, budaya, pendidikan, maupun bidangbidang lain tidak akan dapat terselenggara tanpa perbaikan mental dan moral terlebih dahulu. Untuk itulah, pendidikan moral harus diperhitungkan sebagai landasan titik tolak dalam melakukan perubahan ke arah yang lebih baik.

Di era citizen journalism peranan moral justru menjadi sangat penting. Di era jurnalisme konvensional maka semua tulisan yang akan dipublikasikan atau diterbitkan melalui proses editing di redaksi. Dalam hal ini, redaksi memiliki kriteria tertentu untuk kelayakan suatu tulisan sesuai dengan normal yang berlaku di masyarakat dan serta misi yang diemban. Dengan demikian, tulisan yang muncul di ruang publik terseleksi sesuai dengan standar kelayakan yang digunakan oleh institusi penerbitan. Sebaliknya, di era citizen jiurnalism tulisan yang terpublikasikan tidak melalui seleksi sehingga derajat kelayakan tulisan sepenuhnya diserahkan dan menjadi tanggung jawab penulisnya. Standar moralitas tulisan menjadi sangat beragam dan kompleks sesuai dengan norma dan nilai moral yang dipahami dan digunakan oleh penulisnya. 
WAHANA

Volume 71, Nomor 2, 1 Desember 2019

Kompleksitas era citizen journalism juga menyangkut media yang digunakan dalam memublikasikan tulisan seseorang. Di era citizen journalism, individu menjadi jurnalis yang berbasis internet dengan beragam layanan yang sangat kompleks dengan komunitas yang terbatas (misalnya, grup what-app) maupun yang lebih luas (misalnya face-book) dan terbuka. Demikian pula, pembaca dalam citizen journalism sangat beragam dari berbagai kalangan, komunitas, jenis kelamin, dan usia.

Dari kompleksitas pelaku, media, dan pembaca maka era citizen journalism dituntut adanya tanggung jawab moral yang jauh lebih besar. Era di mana setiap warga menjadi jurnalis sekaligus pembaca. Setiap individu menjadi subjek sekaligus objek atas perannya dalam jurnalistik warga. Dalam posisi seperti ini maka dalam dunia jurnalistik dituntut integritas moral individu sebagai subjek komunikasi (komunikator sekaligus komunikan) untuk menghindari konfliks karena benturan nilai kepantasan dan kebenaran.

Oleh karena itu, era citizen journalism merupakan era banjir informasi. Di mana segala informasi apapun masuk ke ranah privat sekaligus publik setiap individu. Berdasarkan hasil eksplorasi tanggapan mahasiswa hemat penulis, era citizen journalism memiliki bebrapa karakteristik utama berikut.

1. Semua orang adalah jurnalis sekaligus pembaca.

2. Dalam era banjir informasi, maka kita harus menyeleksi informasi dan bukan mencari informasi.

3. Informasi memasuki segala sisi kehidupan kita, batas antara ruang privat dan publik menjadi kabur.
4. Standar moral dan nilai kebenaran suatu berita/informasi menjadi tidak jelas.

5. Individu menjadi subjek sekaligus objek jurnalistik.

Dalam kondisi seperti itu, dibutuhkan standar moral yang dapat digunakan oleh seseorang sebagai acuan dalam mengungkapkan atau mengekspresikan pikirannya. Temuan terhadap eksplorasi sikap atau pandangan mahasiswa terkait dengan citizen journalism, sejalan dengan pandangan Velazquez (2005: 9-10) yang menyatakan bahwa terdapat sejumlah penanda yang dapat digunakan dalam menentukan standar moral, yang meliputi:

1) Standar moral berkaitan dengan persoalan yang merugikan secara serius. Standar moral yang dapat diterima banyak orang, misalnya, perlawanan terhadap pencurian, perkosaan, pembunuhan, dan perbudakan.

2) Standar moral ditetapkan atau diubah oleh keputusan otoritatif tertentu. Meskipun demikian, validitas standar moral terletak pada kecukupan nalar yang digunakan untuk mendukung dan membenarkannya.

3) Standar moral harus diutamakan daripada nilai lain termasuk kepentingan diri. Misalnya, pengutamaan standar moral adalah ketika lebih memilih menolong orang yang jatuh di jalan, ketimbang ingin cepat sampai tempat tujuan tanpa menolong orang tersebut.

4) Standar moral berdasarkan pada pertimbangan yang tidak memihak. Dengan kata lain, pertimbangan yang dilakukan bukan berdasarkan keuntungan atau kerugian pihak tertentu, melainkan memandang bahwa setiap masing-masing pihak memiliki nilai yang sama. 
5) Standar moral diasosiasikan dengan emosi tertentu dan kosa kata tertentu. Emosi yang mengasumsikan adanya standar moral adalah perasaan bersalah, sedangkan kosakata atau ungkapan yang merepresentasikan adanya standar moral yaitu "ini salah saya", "saya menyesal" dan sejenisnya.

6) Standar moral didasarkan pada nilai-nilai kemanusiaan universal. Dengan demikian, dapat berlaku bagi semua orang dan dalam berbagai situasi, misalnya kejujuran, keadilan, toleransi, dan hati nurani.

Pandangan Lickona (1992) dikenal dengan Educating for Character atau pendidikan karakter/watak untuk membangun karakter atau watak individu. Lickona mengacu pada pemikiran filosof Michael Novak yang berpendapat bahwa watak atau karakter seseorang dibentuk melalui tiga aspek yaitu, moral knowing, moral feeling, dan moral behavior, yang satu sama lain saling terkait dan bermakna secara signifikan. Dengan demikian, hasil pembentukan sikap karakter anak pun dapat dilihat dari tiga aspek, yaitu konsep moral, sikap moral, dan perilaku moral.

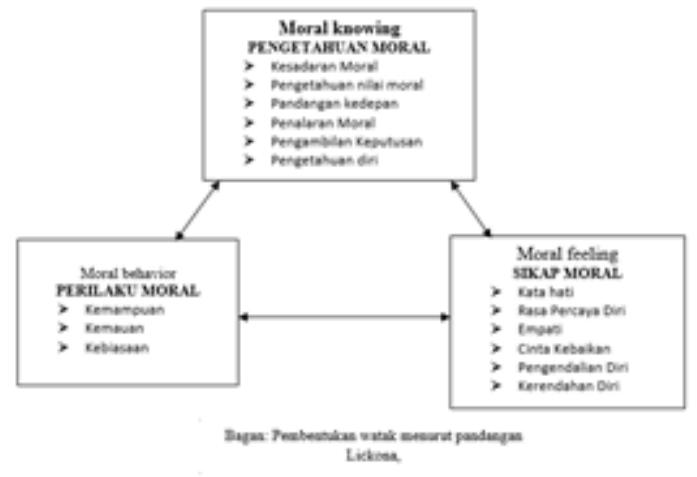

Dalam hal ini, teori moral Lickona diposisikan sebagai titik pijak awal (point of departure) yang bersifat tentatif dan karena itu terdapat ruang yang cukup memadai untuk mengelaborasi dan memasukkan argumentasi teoritis yang berbeda dari pemikiran Lickona tentang pengetahuan, sikap, dan perilaku moral.

Bertolak dari berbagai di atas, kami mengajukan beberapa proposisi teoritis konstruksi moral. Selain itu, proposisiproposisi teoritis ini digunakan sebagai bingkai atau penuntun umum dalam memahami posisi moralitas dalam jurnalistik era citizen journalism. Dalam makalah ini, setidaktidaknya terdapat sembilan proposisi tentang moral yang dapat dikemukakan sebagai berikut. (1) Moral hanya relevan dalam hubungannya dengan individu atau kelompok lain. Dengan kata lain, eksistensi moral selalu terikat oleh konteks sosial. (2) Eksistensi moral tidak pernah tunggal melainkan jamak (multiplecity of moral) dan selalu berubah dari satu konteks sosial ke konsteks yang lain. (3) Kejamakan moral tidak hanya dipresentasikan melalui pernyataan diri (self expression), melalui simbol dan atribut yang kompleks, melainkan juga lapis-lapis yang berbeda kedalamannya (multilayers of moral). (4) Moral dibentuk oleh berbagai ragam elemen yang menghasilkan formasi moral yang dinamis. Dengan demikian, terdapat ruang yang terbuka bagi individu maupun kelompok untuk mengkonstruksi dan merekonstruksi moralnya sesuai dengan konteks di mana moral tersebut dipresentasikan. (5) Moral ditransaksikan dari waktu ke waktu dalam dan melalui interaksi sosial. (6) Individu selalu terlibat dalam pergumulan di antara, di satu pihak, kebutuhan untuk mengkonstruksi moral dan dipihak lain, tuntutan untuk merespon tindakan sosial yang diberikan oleh individu atau kelompok lain. (7) Dalam masyarakat, moral tidak saja berfungsi sebagai penanda (marker) dan pembeda (signifer) melainkan 
juga sebagai pengada (being maker). (8) Dalam masyarakat, proses mengonstruksi, mendekonstruksi, atau merekonstruksi senantiasa terjadi dalam sebuah spektrum yang bergerak dari asimilasi dan akulturasi hingga rivalitas, kompetisi, dan bahkan konflik. (9) proses mengonstruksi moral tidak sepenuhnya bebas dari interelasi struktur dan otoritas.

Menurut Lieebert (dalam Kosasih, 1992, hlm. 6) Moral mengandung esensi dari kandungan moral adalah "interpersonal relationship and transactions". Makna dari pernyataan tersebut bahwa moral memiliki dimensi personal-spiritual (transactions) dan interpersonal-sosial (interpersonal relationship), dimana orang bermoral adalah orang yang baik sebagai mahluk individu atau sebagai mahluk sosial. Sedangkan Bull (1983, hlm. 3; Jana, 2007, hlm. 167) menyatakan bahwa pertama, moral berhubungan dengan "Code of conduct in society". Kedua, moral berhubungan dengan "the pursuit of the good life". Jadi moral tidak saja bersifat heteronom, tetapi juga bersifat otonom.

Pada hakikatnya moral berkaitan erat dengan perilaku seseorang dalam bertindak dan berbuat dalam kehidupan sehari-hari. Hurlock (1990: 74; Colby, 2000: 3) berpendapat bahwa perilaku moral berarti perilaku yang sesuai dengan kode moral kelompok sosial, perilaku moral yang dikendalikan konsep-konsep moral, peraturan perilaku yang telah menjadi kebiasaan bagi anggota suatu budaya dan yang menentukan pola perilaku yang diharapkan dari seluruh anggota kelompok.

\section{KESIMPULAN}

Jurnalisme 4.0 atau era citizen journalism menuntut adanya integritas moral yang kuat dari masing-masing individu karena setiap orang adalah subjek sekaligus objek jurnalistik. Media jurnalistik yang ada (berbasis internet) telah memasuki ranah privat sekaligus publik setiap individu. Dalam kompleksitas yang amat tinggi tersebut maka dituntut kehadiran moralitas individu agar tidak mengoyak nilai-nilai kepantasan dan kebenaran dalam jurnalistik. Dengan demikian, setiap individu harus bertanggung jawab dan mempertanggungjawabkan semua pernyataannya di ranah publik. Tanggung jawab tersebut secara dominan terkait dengan moralitas atau integritas moral individu dalam partisipasinya di medan jurnalistik era citizen journalism.

\section{REFERENSI}

Kohlberg, L. \& Hersh, R. 1977. Moral development: a review of the theory, Theory Into Practice, 16(2), 53-59. Doi:101080/0040584770954267

Berger, Peter L., Thomas Luckmann. 1990. Tafsir Sosial Atas Kenyataan: Risalah tentang Sosiologi Pengetahuan. Jakarta: LP3ES.

De Vaus, D.A., 2002. Surveys In Social Research. Allen \& Unwin: Australia.

Goffman, Erving. 1959. The Presentation of Self In Everyday Life. New York: Doubleday Anchor.

Kohlberg, L. (1981). Essays on Moral Development. The Philosopy of Moral Development. Vol I. San Fransisco: Harper \& Row Publisher

Lickona, T. (1992). Education for Character: How Our Schools Can Teach Respect and Responsibility. New YorkToronto: Bantam. 
WAHANA

e-ISSN 2654-4954, p-ISSN 0853-4403

Volume 71, Nomor 2, 1 Desember 2019

Muhadjir, Noeng. 2002. Metodologi Penelitian Kualitatif. Rake Sarasin: Yogyakarta.

Ritzer, George. 2012. Sociological Theory.

New York: McGraw-Hill.

Zuriah, N. (2007). Pendidikan Moral \& Budi Pekerti Dalam Perspektif Perubahan: Menggagas Platfom Pendidikan Budi

Pekerti secara Kontekstual dan

Futuristik. Jakarta:Bumi Aksara 
Volume 71, Nomor 2, 1 Desember 2019 